\title{
Niche divergence corresponds to genetic differentiation within the parrot-beaked tortoise Homopus areolatus (Reptilia: Testudinidae), endemic to South Africa
}

\author{
MARGARETHA D. HOFMEYR ${ }^{1, \dagger, \oplus}$, FLORA IHLOW $^{2}$, PIERRE FOUCHE $^{1}$ and \\ SAVEL R. DANIELS 3 ,* \\ ${ }^{1}$ Chelonian Biodiversity and Conservation, Department of Biodiversity and Conservation Biology, \\ University of the Western Cape, Bellville 7535, South Africa \\ ${ }^{2}$ Museum of Zoology, Senckenberg Dresden, Dresden, Germany \\ ${ }^{3}$ Department of Botany and Zoology, University of Stellenbosch, Private Bag X1, Matieland 7602, South \\ Africa
}

Received 4 May 2019; revised 19 February 2020; accepted for publication 8 March 2020

\begin{abstract}
We assessed genetic differentiation and habitat suitability for Homopus areolatus during current and Last Glacial Maximum (LGM) conditions. The ND4 locus retrieved two monophyletic mtDNA clades with lower diversity in clade 1 , in the west, than in clade 2 , in the south-east. Clade 1 showed a north-south and clade 2 a west-to-east genetic divergence, and the clades co-occur in the syntaxis zone of the Cape Fold Mountains. The clades occupy distinct niches with limited overlap. Rainfall seasonality contributed most to habitat suitability, with clade 1 being restricted to winter rainfall and clade 2 to all-year rainfall regions. Precipitation variables contributed $90 \%$ and $60 \%$, respectively, to habitat suitability of clades 1 and 2, with temperature, particularly mean temperature of the driest quarter, being of greater importance for clade 2 than clade 1. Suitable habitat shrank from the LGM to current conditions, probably due to reduced rainfall in the west and higher temperatures in most regions. We conclude that patterns of genetic divergence are strongly associated with ecological niche divergence of $H$. areolatus clades. More studies are needed to assess the taxonomic status of clade 1, particularly in view of its shrinking habitat due to climate change and anthropogenic factors.
\end{abstract}

ADDITIONAL KEYWORDS: Albany Thicket - Cape Fold Mountains - fynbos - glaciation - last glacial maximum - niche models - niche overlap - palaeoclimate - Pleistocene - Pliocene.

\section{INTRODUCTION}

The Greater Cape Floristic Region (GCFR) of South Africa constitutes a north-westerly expansion of the southern Cape Floristic Region (CFR), to combine the western Succulent Karoo with the fynbos and thicket vegetation of the CFR (Born et al., 2007). In the west, the GCFR receives winter rainfall, whereas the southern and eastern parts receive all-year rains. Floral and faunal diversity in the GCFR and CFR are attributed mainly to climate fluctuations following the Middle-Miocene Climatic Optimum (17 to 15 Mya;

*Corresponding author. E-mail: srd@sun.ac.za

Deceased.
Tolley et al., 2014; Hoffman et al., 2015; Neumann $\&$ Bamford, 2015). Due to decreasing temperatures, the Antarctic ice-sheet was re-established by 10 Mya but temperature decline was interrupted by a warming trend (5-3 Mya) in the Early Pliocene (Zachos et al., 2001; Fedorov et al., 2006). In addition to global cooling, Milankovitch caused glaciers to wax and wane, resulting in oscillations between ice ages and interglacial periods, the intensity of which increased substantially from the Late Pliocene (3 Mya) throughout the Pleistocene (Fedorov et al., 2006). These climatic fluctuations caused sea levels to rise and fall repeatedly, and strongly influenced species distributions, leading to repeated shifts, contractions or expansions in range (Hewitt, 2000). 
Apart from temperature fluctuations, southern Africa became progressively more arid since the Oligocene (Burke \& Gunnell, 2008), particularly in the west, after the proto-Benguela Current became established about 14 to 10 Mya and intensified about 5 to 3 Mya (Rommerskirchen et al., 2011; Hoffmann et al., 2015 and references therein). The development of the Benguela Current also brought about changes in rainfall seasonality and established summer aridity in the western regions of South Africa during the Late Miocene, the time when current biomes developed fully (Hoffmann et al., 2015; Neumann \& Bamford, 2015).

Cladogenesis of the rich southern African tortoise fauna started in the Eocene and Oligocene, with radiation events increasing in the Miocene and Pliocene (Hofmeyr et al., 2017). Among these tortoises are the five padloper species, which are all dorsoventrally flattened, dwarf tortoises. Historically, all dwarf tortoises were included in the genus Homopus, but a phylogenetic study by Hofmeyr et al. (2017) demonstrated that the three five-toed Homopus species form a clade with Chersina angulata (Schweigger, 1812), rendering Homopus paraphyletic. Hofmeyr \& Branch (2018) resurrected the genus Chersobius to accommodate the five-toed padloper species and retained only the two four-toed padloper species in Homopus: H. areolatus (Thunberg, 1787) and H. femoralis Boulenger, 1888. The two Homopus species diverged towards the Late Oligocene, whereas the three Chersobius species differentiated in the Miocene. Hofmeyr et al. (2017) also showed substantial divergence within $H$. areolatus since the Late Miocene.

Homopus areolatus is endemic to South Africa where it is found in the south-west and south-east below the Great Escarpment (GE), including valleys of the Cape Fold Mountains (CFMs); a few populations, presumably relictual, occur above the GE in the Northern Cape Province (Hofmeyr et al., 2014). The GE of South Africa constitutes a horseshoe-shaped rim 50-200 $\mathrm{km}$ inland and parallel to the South African coastline, which separates the lower lying coastal plains from the elevated African plateau (Moore et al., 2009; Clark et al., 2011; Grab \& Knight, 2015). The CFMs form as a southern west-to-east belt, a western south-to-north belt and a syntaxis zone in the south-west where the two belts meet (Partridge et al., 2010). The topographic features associated with the distribution of $H$. areolatus are generally believed to date back much further than radiations within the species. The CFMs were already formed before rifting of Gondwanaland in the Lower Cretaceous (Grab \& Knight, 2015), and most authors agree that the position of the GE dates to the Cretaceous (Clark et al., 2011). Nevertheless, several studies provide evidence that more recent uplift events and subsequent erosion contributed to the current relief of the GE, and some mountain ranges of the CFMs (Burke \& Gunnell, 2008; Green et al., 2017). Partridge (1997) proposed that a relatively mild epeirogenic uplift in the Early Miocene (20-18 Mya) was followed by a more extensive uplift in the Pliocene (5-3 Mya), with both uplifts having substantial effects in eastern South Africa, but only minor effects in the interior and west. It appears that erosion, following the Early Pliocene uplift, exposed clay-rich shale and mudstone, which increased habitat heterogeneity, and, together with Pliocene-Pleistocene climate variation, the diversification of plants in the GCFR (Cowling et al., 2009; Hoffmann et al., 2015).

Homopus areolatus shows a strong affiliation to fynbos and renosterveld vegetation of the Fynbos Biome and penetrates open thicket vegetation of the Albany Thicket Biome to the east (Branch, 2008; Hofmeyr et al., 2014). These vegetation types of the CFR receive more rain than the adjacent Succulent and Nama Karoo (Rutherford et al., 2006; Born et al., 2007). Of these vegetation types, Albany Thicket is the oldest, dating to the Palaeogene (Cowling et al., 2005), whereas fynbos vegetation consists mainly of Miocene-Pliocene lineages, associated with western summer aridity and lowland vegetation (Linder, 2008; Cowling et al., 2009; Verboom et al., 2014). Renosterveld lineages of the Fynbos Biome developed primarily in shale substrata in the CFR, in response to climatic and edaphic conditions during the Pliocene (Cowling et al., 2009; Hoffmann et al., 2015).

In recent years, many researchers combined phylogeographic evaluations of taxa with ecological niche-modelling approaches to test if lineage and niche divergences correspond (Raxworthy et al., 2007; Rissler \& Apodaca, 2007; Alvarado-Serrano \& Knowles, 2014). Genetic variation is often associated with palaeoclimatic fluctuations; thus, projecting environmental niche models onto climatic conditions of historic extremes, such as the last glacial maximum (LGM), helps to explore past range contractions and expansions. Therefore, such models help to identify regions of environmental stability where species might have persisted in climatically advantageous refugia, but also reveal regions that have likely been uninhabitable (Alvarado-Serrano \& Knowles, 2014; Wang et al., 2017; Nicolas et al., 2018).

Barlow et al. (2013) combined a range-wide genetic evaluation of the African puff adder, Bitis arietans (Merrem, 1820) with climatic niche modelling and concluded that themtDNAclades diverged in the Pliocene and Pleistocene, with glacial maximum climates being the primary factor that has driven range fragmentation and subsequent genetic diversification. Their results showed western and eastern mtDNA clades in the CFR, which they considered an important refugial area during Plio-Pleistocene climatic fluctuations. A similar west-to-east differentiation in the CFR has been shown 
for several other animal and plant species (Tolley et al., 2014 and references therein), as well as for chelonians, e.g. for the tortoise Chersina angulata (Daniels et al., 2007) and the terrapin Pelomedusa galeata (Schoepff, 1792) (Vamberger et al., 2018).

For this study, we combined phylogenetic analyses with ecological niche modelling, for current and palaeoclimatic conditions, to test some biogeographic hypotheses. Because $H$. areolatus has low vagility (BT Henen \& MD Hofmeyr, unpubl. data), we hypothesized that its genetic structure would be influenced by geographical barriers and abiotic gradients across its range. In particular, we proposed that southwestern populations inhabiting the winter rainfall region would be genetically distinct from southeastern populations that experience all-year rain. Linked to this hypothesis is the assumption that niche divergence would correspond to genetic differentiation within $H$. areolatus. We also tested for the expansion or contraction of suitable habitat between glaciation (LGM) and interglacial (current) conditions to assess how climatic fluctuations could have influenced the distribution of clades, and thus divergences among $H$. areolatus populations from different regions.

\section{MATERIAL AND METHODS}

\section{SAMPLE COLLECTION}

We collected genetic samples of 69 Homopus areolatus specimens from 26 localities throughout the distribution of the species in the Western Cape, Eastern Cape and Northern Cape Provinces of South Africa (Fig. 1; Supporting Information, Table S1). Blood of live tortoises was collected from either the jugular or subcarapacial vein and diluted with absolute ethanol for storage. Fresh and dried carcases collected in the field were biopsied for muscle tissue or bone, respectively. While bone samples were kept dry, muscle tissue was stored in absolute ethanol, with all tissue samples being transferred to $-20{ }^{\circ} \mathrm{C}$ upon return to the laboratory. The geographic coordinates of each sample were recorded in the field or, in a few instances, estimated from maps.

\section{DNA EXTRACTION, PCR AND SEQUENCING}

For a detailed outline of the DNA extraction, primer pairs used, PCR conditions and DNA-sequencing protocol, consult Hofmeyr et al. (2017). We sequenced all $69 \mathrm{H}$. areolatus specimens for the mitochondrial DNA nicotinamide adenine dinucleotide dehydrogenase component four locus (hereafter ND4). This locus is a rapidly evolving mitochondrial marker and has been used in a variety of evolutionary studies on tortoises (Parham et al., 2006; Ives et al., 2008; Fritz et al., 2010; Daniels et al., 2007, 2010). In addition to the ND4 locus, we also employed the nuclear DNA prolactin locus to examine the degree of genetic differentiation between the two clades detected by a preliminary analysis of the ND4 locus. For prolactin, we selected 17 individuals for sequencing, representative of the

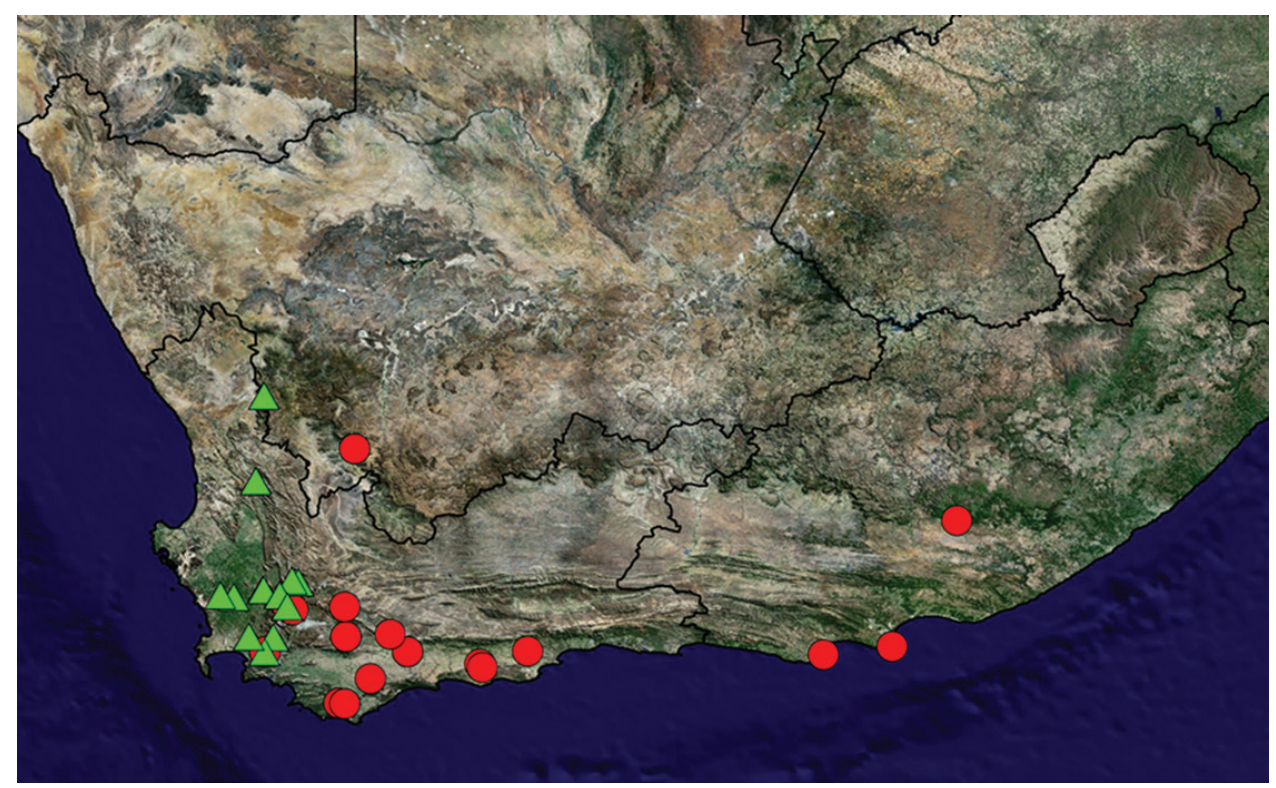

Figure 1. Distribution of Homopus areolatus genetic samples with green triangles representing clade 1 in the west and red circles representing clade 2 in the south-east. Note that clades 1 and 2 overlap in the syntaxis zone of the Cape Fold Mountains (Figs 3 and 4). 
haplotype range detected in the two ND4 clades (see Results for description of the clades). The prolactin locus has been demonstrated to exhibit varying degrees of genetic variability in reptiles (Townsend et al., 2008), including tortoises, and has been used with success in the latter group (Daniels et al., 2010; Hofmeyr et al., 2017).

\section{NETWORK RECONSTRUCTION}

Sequence navigator (Applied Biosystems) was used to compute a consensus sequence for both forward and reverse strands. We aligned the sequences in Clustal X (Thompson et al., 1997) using the default parameters of the program. No insertions or deletions were observed. Haplotype networks for prolactin and ND4 were constructed separately using TCS (Clement et al., 2000) with a 95\% parsimony probability. We performed an analysis of molecular variation on the data (AMOVA) using ARLEQUIN v.3.0 (Excoffier et al., $2005)$ to, first, calculate variation across all sample localities $\left(\Phi_{\mathrm{ST}}\right)$ and, second, to calculate the degree of genetic variation within each of the two ND4 clades detected during a preliminary analysis. Permutation procedures used 10000 randomizations to test for significance. Deviations in neutrality were investigated with Fu's $F_{s}$ test (Fu, 1997) using ARLEQUIN v.3.0. Our preliminary analyses revealed the presence of two ND4 clades, with some haplotypes that could not be detected using the $95 \%$ confidence interval; hence, we also undertook a tree reconstruction.

\section{PHYLOGENETIC ANALYSES}

Maximum likelihood (ML) and Bayesian inference (BI) approaches were used to estimate the relationships among haplotypes. Phylogenetic analyses of the southern African tortoise fauna suggest that Homopus areolatus is sister to $H$. femoralis (Hofmeyr et al., 2017); hence, three specimens of the latter species were used as outgroups.

For ML, phylogenetic analyses were executed in PAUP* 4 version beta 10 (Swofford, 2002). Phylogenetic confidence in nodes was estimated by bootstrapping (Felsenstein, 1985), analysing 100 pseudoreplicates of datasets. Bootstrap values $\geq 75 \%$ were considered well supported. Bayesian inferences were used to investigate optimal tree space using the program MrBayes 3.0b4 (Ronquist \& Huelsenbeck, 2003) and the models were selected from MODELTEST v.3.06 using the AIC criteria (Posada \& Crandall, 1998). For each analysis, four Markov chains were run, with each chain starting from a random tree and run for 5 million generations, sampling each chain every $10000^{\text {th }}$ tree. This process was repeated four times for each gene fragment to ensure that all consensus trees converged on the same topology. A 50\% majority rule consensus tree was generated from the trees retained (after the burn-in trees were discarded - using likelihood plots) with posterior probabilities (PP) for each node estimated by the percentage of time the node was recovered. Posterior probability values $\geq 0.95 \mathrm{PP}$ were considered statistically supported. Uncorrected ('p') sequence distances among sample sites were calculated in PAUP and compared to those for others studied with uncorrected values.

\section{DIVERGENCE TIME ESTIMATION}

We could not use fossil data in the analysis because the only known Homopus fossil, H. fenestratus (Cooper \& Broadley, 1990), originated from an uncertain horizon from the Albany District and is not dated. Consequently, we employed mutation rates to estimate the divergence within $H$. areolatus. To determine the divergence time estimations for the latter species we applied a Yule tree prior and an uncorrelated lognormal relaxed molecular clock after initial test runs (investigating if the standard deviation of the uncorrelated lognormal clock approaches zero). We used substitution rates (and their standard deviation) from studies on the mitochondrial genome of tortoises and turtles (Bowen et al., 1992; Lamb et al., 1994; Caccone et al., 1999; Shaffer et al., 2013) as priors, resulting in a mutation range of $0.33-0.60$ per Myr for the ND4 data. The maximum clade credibility tree was determined and annotated in TreeAnnotator v.2.4.1 (part of the Beast package) after removal of $10 \%$ of the trees as burn-in. We are cognizant that this analysis provides only a relative estimation of divergence within the taxon, but it may nevertheless facilitate understanding the biogeographic factors that resulted in cladogenesis.

\section{CLIMATIC NICHE MODELS AND NICHE CHARACTERISTICS}

We computed correlated niche models for $H$. areolatus and the two genetically distinct clades to assess if environmental profiles differ among the species and its clades. Subsequently these models were projected onto palaeoclimatic conditions of the LGM (21 000 years ago) to investigate how past climate fluctuations and related eustatic sea-level changes have influenced current distributions. For both current and past analyses, we used SDMtoolbox 2.4 (Brown 2017; Brown et al., 2017) in combination with MAXENT 3.4.1 software (Phillips et al., 2006). We supplemented our list of genetic samples with data from the South African Reptile Conservation Assessment 
(a compilation of localities for reptile species from museum records and conservation agencies; see Bates et al., 2014). To prevent spatial autocorrelation, we used the SDMtoolbox v.2.4 (Brown 2017; Brown et al., 2017; Boria et al., 2014) to spatially filter the resulting dataset to a Euclidian distance of $2.5 \mathrm{~km}$, retaining 262 unique localities for $H$. areolatus (Fig. 2). Because our genetic analyses detected two localities in the syntaxis zone of the CFMs (Partridge et al., 2010) where western and south-eastern clades co-occur (see Fig. 1), we removed non-genetic samples from this zone (26 points) and retained 80 and 156 unique localities, inclusive of the genetic samples, for separate models of the western and south-eastern clades, respectively (Fig. 2).

The following nine uncorrelated $\left(\mathrm{R}^{2} \leq 0.75\right)$ predictor variables with a spatial resolution of 2.5 arc-minutes $(\sim 4 \mathrm{~km}$ at the equator) were selected for both current (1970-2000) and past (LGM) climatic conditions (http://worldclim.org; Hijmans et al., 2005; Fick \& Hijmans, 2017): BIO 2 (mean diurnal temperature range), BIO 3 (isothermality), BIO 6 (minimum temperature of the coldest month), BIO 8 (mean temperature of the wettest quarter), BIO 9 (mean temperature of the driest quarter), BIO 12 (annual precipitation), BIO 14 (precipitation of the driest month), BIO 15 (precipitation seasonality) and BIO 19 (precipitation of the coldest quarter). For the LGM, we obtained three reconstructions, derived from global circulation models, namely the Community Climate System Model (CCSM4; Otto-Bliesner et al., 2006), the Max-Planck-Institute Earth System Model P (MPIESM-P) and the Model for Interdisciplinary Research on Climate (MIROC; Hasumi et al., 2004).

We used circular buffers with a radius of 200 km (see: VanDerWal et al., 2009), surrounding the occurrence records of each group (Supporting Information, Fig. S1) to extract background points for model training, and projected the results into the full study extent, a rectangular area covering current and past conditions. Models for current climatic conditions for $H$. areolatus and the two genetically distinct clades were computed using MAXENT v.3.4.1 (Phillips et al., 2006; Phillips \& Dudík, 2008; Phillips et al., 2019). We applied a bootstrapping approach with 100 replicates and 5000 iterations splitting the dataset randomly into $80 \%$ used for model training and $20 \%$ used for model evaluation. We allowed automatic feature and regularization parameter selection. The average projections across all 100 replicates were used for further processing, wherein the 'minimum training presence' presence-absence threshold was applied. Subsequently, environmental predictor variables were jackknifed to measure the importance of each variable. The resulting models were then projected onto the three LGM reconstructions. The area under the curve (Swets 1988) was used for model evaluation. To correct for model overprediction, we used SDMToolbox to clip models by a fixed buffered area $(200 \mathrm{~km}$ radial buffer for each of the three groups) based on the localities used to build the model (Brown et al., 2017).

In order to assess distribution changes between LGM and current suitable habitats, we used ArcGIS to calculate suitable habitat of current and LGM binary maps (clipped to remove overpredictions), and overlapped corresponding maps with the Intersect Tool of ArcGIS to visualize changes in suitable habitat. In addition, we used ENMTools (Warren et al., 2010) to assess niche overlap (Warren et al., 2008) by using Schoener's $D$ and Hellingers' $I$ statistics. Both metrics range from 0 to 1 , with 0 indicating completely dissimilar niches, whereas 1 indicates identical niches.

\section{RESULTS}

We successfully amplified a 680 base pair (bp) fragment of the ND4 locus for the 69 Homopus areolatus specimens. These novel ND4 sequences were deposited in GenBank (accession numbers MN245571MN245639). The DNA substitution model retrieved for the ND4 locus using the AIC criteria was TVM+G, the base frequencies were $\mathrm{A}=27.96 \%, \mathrm{C}=12.61 \%$, $\mathrm{G}=24.58 \%$ and $\mathrm{T}=34.84 \%$, the rate matrix was $\mathrm{R}(\mathrm{a})$ $[\mathrm{A}-\mathrm{C}]=0.00 ; \mathrm{R}(\mathrm{b})[\mathrm{A}-\mathrm{G}]=6.15 ; \mathrm{R}(\mathrm{c})[\mathrm{A}-\mathrm{T}]=0.57 ; \mathrm{R}(\mathrm{d})$ $[\mathrm{C}-\mathrm{G}]=1.33 ; \mathrm{R}(\mathrm{e})[\mathrm{C}-\mathrm{T}]=6.15$ and $\mathrm{R}(\mathrm{f})[\mathrm{G}-\mathrm{T}]=1.00$ and the gamma was 0.52

For the nuclear DNA prolactin locus, we sequenced a $514 \mathrm{bp}$ fragment for 17 specimens representing the two divergent ND4 clades. The novel prolactin sequences were deposited in GenBank (accession numbers MN245640-MN245656).

\section{NETWORK RECONSTRUCTION}

We retrieved only two haplotypes, with no geographic structure, from prolactin sequences of $17 \mathrm{H}$. areolatus. In contrast, the TCS analyses of 69 ND4 sequences yielded 30 haplotypes in two haploclades (Fig. 3; Supporting Information, Table S2). Haploclade 1 contained 11 haplotypes, with the specimen from Oorlogskloof Nature Reserve (haplotype 3) in the Northern Cape Province being genetically isolated and unconnected to the remainder of the network. Haploclade 2 contained 19 haplotypes, with samples from the Little Karoo between the CFMs (haplotypes 14 and 15) and above the GE (haplotype 13) being connected by a minimum of eight unsampled or missing haplotypes from the remainder of the southern Cape coastal samples, while the three samples (haplotype 

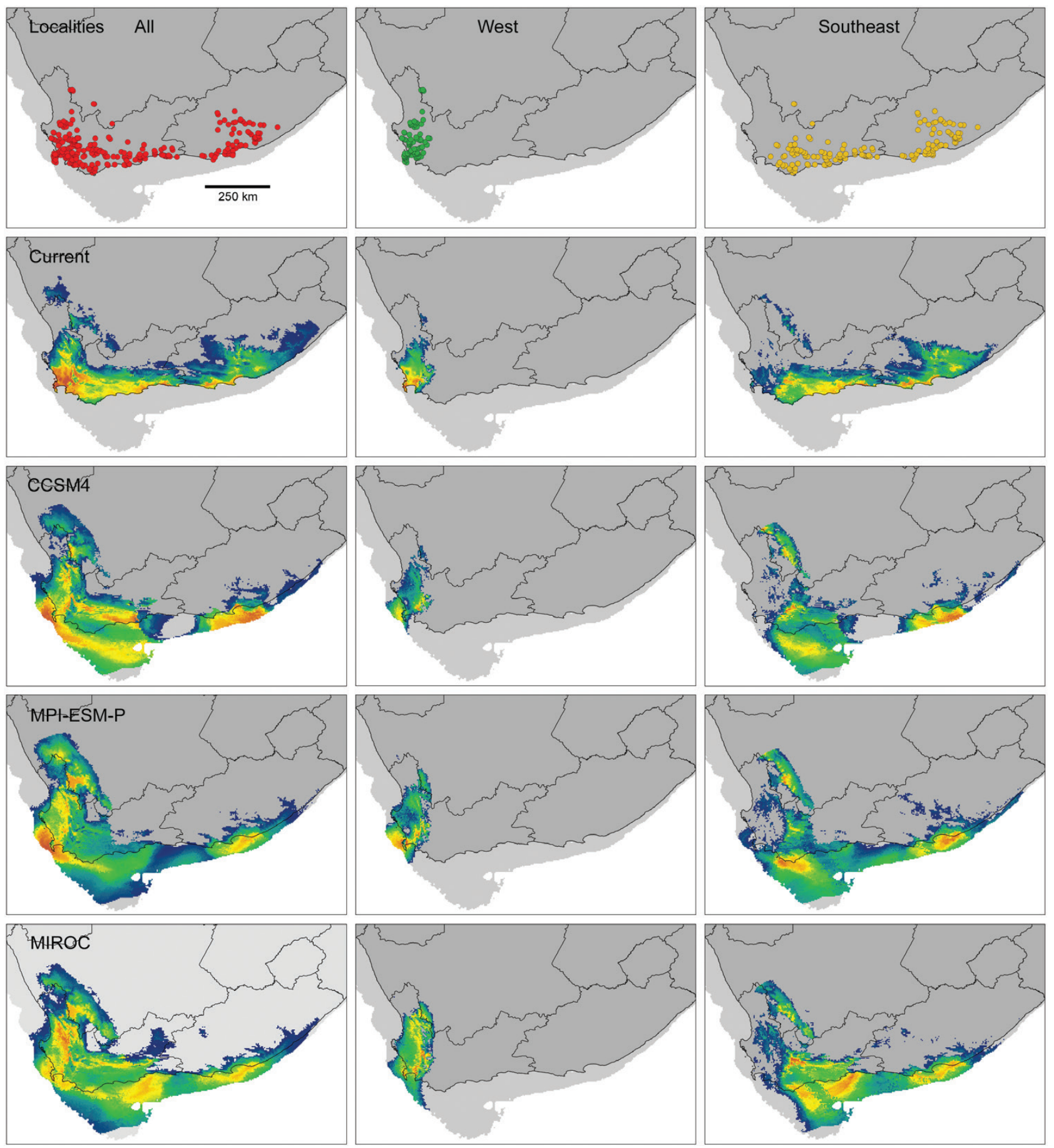

Figure 2. Distribution records of Homopus areolatus and its clades used for niche modelling after spatial filtering to a Euclidian distance of $2.5 \mathrm{~km}$ (top row). Potential distributions, corrected for overprediction, of $H$. areolatus (left) and the genetically distinct western (middle) and south-eastern (right) clades as derived from maximum entropy models for current and last glacial maximum (LGM) climates with the latter attained from the global circulation models CCSM4, MPI-ESM-P and MIROC-ESM. Habitat suitability ranges from low/moderate (dark blue) to high (red). Note that the sea level was substantially lower during the LGM.

12) from the Eastern Cape Province were unconnected to the main network. The latter results suggest higher genetic variation in haploclade 2 in comparison to haploclade 1.
For the AMOVA across all sample localities, the $\Phi_{S T}$ was 0.78 and is considered high. These results revealed that $78.42 \%$ of the variation occurred among populations (d.f. 26; sum of squares [SS] 355.77; 


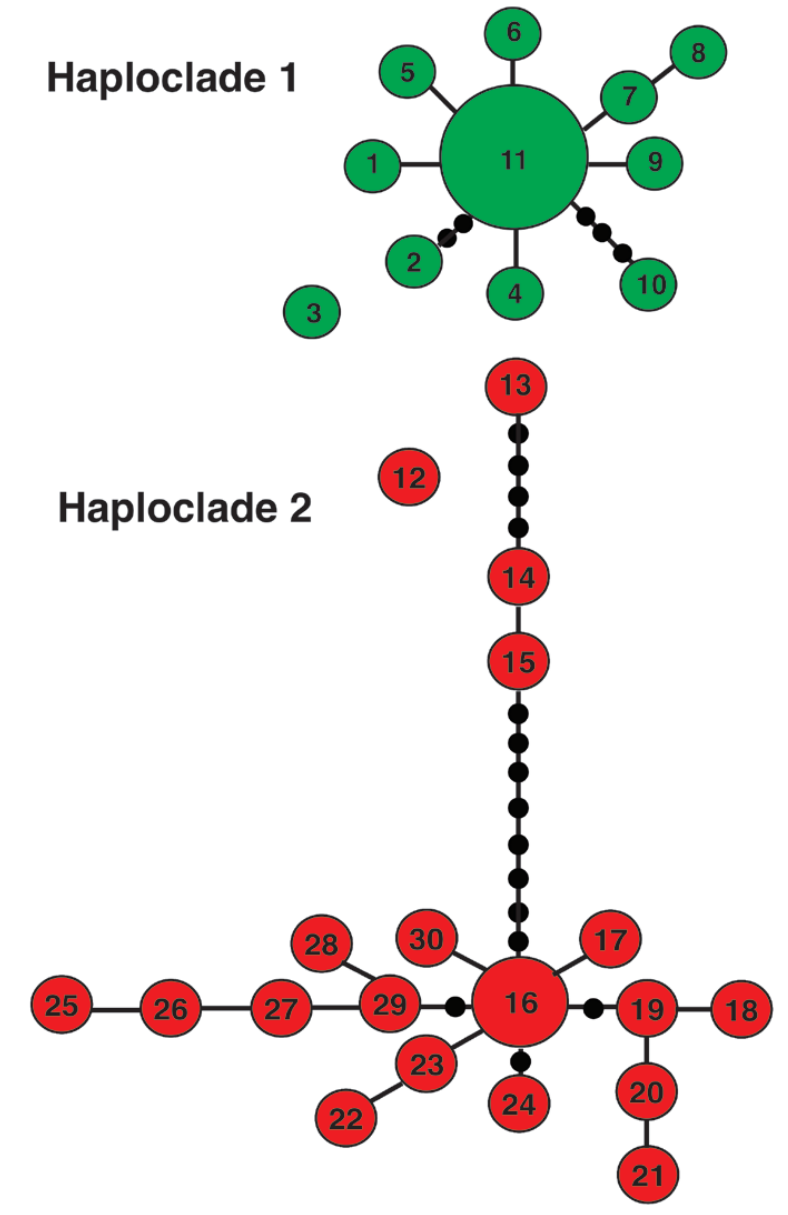

Figure 3. TCS haplotype network of ND4 for haploclade 1 in the west and haploclade 2 in the south-east. Note that for haploclade 1 the sample above the Great Escarpment (haplotype 3 at Oorlogskloof) is unconnected to the network. Similarly, for haploclade 2, samples from the east (haplotype 12; Adelaide, Paradys, Port Elizabeth) are unconnected to southern coastal plains populations. The latter are connected to populations between the Cape Fold Mountains (haplotypes 14 and 15; Montague-Barrydale Road and Sandvlei farm) and above the Great Escarpment (haplotype 13; Blomfontein farm).

variation among [Va] 5.04), while $21.58 \%$ of the variation occurred within populations (d.f. 42 , SS 58.34; variation within [Vb] 1.38). Within haploclade $1, \Phi_{S T}$ was 0.49 , indicating that nearly half, $49.82 \%$ of the variation occurred among populations (d.f. 12; SS 18.56 ; Va 0.46 ), while $50.18 \%$ of the variation occurred within populations (d.f. 22, SS 10.26; Vb 0.46). The high $\Phi_{S T}$ of 0.74 within haploclade 2 revealed that $74.40 \%$ of the variation occurred among populations (d.f. 15; SS 102.73; Va 74.40), while $25.60 \%$ of the variation occurred within populations (d.f. 18, SS 17.97; $\mathrm{Vb} 0.99)$. A summary of the genetic diversity indices for $H$. areolatus is provided (Table 1 ). For most sample localities, Fu's $F_{s}$ could not be calculated due to the presence of a single haplotype. We observed three negative and four positive $F_{s}$ values, but only one $F_{s}$ value from Buffeljags River (-3.514) was statistically significant. Negative values can be attributed to an excess of low frequency polymorphisms consistent with population expansions or positive directional selection. In contrast, positive values indicate an excess of intermediate polymorphisms due to recent population bottlenecks or balancing selection.

\section{PHYLOGENETIC ANALYSES}

The ML and BI analyses for ND4 retrieved identical tree topologies, hence only the BI topology is shown and discussed. Two statistically monophyletic clades $(\geq 75 \% / \geq 0.95 \mathrm{PP})$ are retrieved for $H$. areolatus (Fig. 4), corresponding to the two haploclades of the network reconstruction. Clade 1 comprises of a single specimen from Oorlogskloof Nature Reserve in the Northern Cape Province as sister to samples that are predominantly from the south-western region of the Western Cape Province, but this divergence receives poor support $(<75 \% /<95 \mathrm{PP})$. Clade 2 has substantial substructure, which receives strong support. Samples from valleys between the CFMs and above the GE are differentiated from the coastal population, with the last consisting of two sister-groups from the southern and eastern coastal regions, respectively. The maximum uncorrected 'p' distance within clade 1 is $1.91 \%$, the maximum uncorrected ' $p$ ' sequence distance within clade 2 is $2.35 \%$, while the maximum uncorrected 'p' sequence distance between the two clades is $3.38 \%$. The two prolactin haplotypes have a maximum uncorrected 'p' distance of $0.19 \%$.

Our divergence estimation based on mutation rate shows that radiation within $H$. areolatus started 2.87 Mya (95\% HDP 2.06-3.74 Mya). Clade 1 diverged 1.99 Mya (95\% HDP 1.27-2.80 Mya), while clade 2 diverged 2.05 Mya (95\% HDP 1.39-1.72 Mya) (Fig. 4).

\section{CLIMATIC NICHE MODELS AND NICHE CHARACTERISTICS}

Model performance was excellent with high AUC values exceeding 0.94 for the training and 0.91 for the test dataset across all replicate runs (Table 2). The importance of environmental variables differed between clades, and per cent contribution (PC) and permutation importance (PI) often did not always identify the same variables as making the highest contribution (Table 3). Following the example of several other authors (Aguirre-Gutiérrez et al., 2015; Searcy \& Shaffer, 2016; Zhu et al., 2016), we placed 
Table 1. Diversity measures for Homopus areolatus at localities where sample size exceeded one*. $N$ the number of samples, $N h$ the number of haplotypes, $N p$ the number of polymorphic sites, $h$ the gene diversity, $\pi$ the nucleotide diversity and $\mathrm{Fu} F$ 's. The bold value is statistically significant $(P<0.02)$

\begin{tabular}{|c|c|c|c|c|c|c|}
\hline Locality & $N$ & $N h$ & $N p$ & $h$ diversity & $\pi$ diversity & $\mathrm{Fu} F \mathrm{~s}$ \\
\hline Blomfontein farm & 3 & 1 & 0 & $0.000 \pm 0.000$ & $0.000 \pm 0.000$ & N/A \\
\hline Buffeljags River & 6 & 6 & 6 & $1.000 \pm 0.096$ & $0.004 \pm 0.003$ & -3.514 \\
\hline Elandsberg Reserve & 14 & 4 & 8 & $0.396 \pm 0.159$ & $0.002 \pm 0.001$ & -0.128 \\
\hline Franschhoek & 3 & 2 & 2 & $0.667 \pm 0.314$ & $0.002 \pm 0.002$ & 1.060 \\
\hline Hottentots Holland Reserve & 8 & 5 & 22 & $0.786 \pm 0.151$ & $0.010 \pm 0.006$ & 1.417 \\
\hline Kosierskraal farm & 2 & 2 & 7 & $1.000 \pm 0.500$ & $0.010 \pm 0.011$ & 1.946 \\
\hline Langfontein farm & 4 & 2 & 1 & $0.667 \pm 0.204$ & $0.001 \pm 0.001$ & 0.540 \\
\hline Romans River & 3 & 2 & 0 & $0.667 \pm 0.314$ & $0.000 \pm 0.000$ & N/A \\
\hline Somerset West & 3 & 2 & 2 & $0.667 \pm 0.314$ & $0.002 \pm 0.002$ & -0.128 \\
\hline Still Bay & 2 & 2 & 1 & $1.000 \pm 0.500$ & $0.002 \pm 0.002$ & 0.000 \\
\hline Swartwalle farm & 3 & 2 & 21 & $0.667 \pm 0.314$ & $0.021 \pm 0.016$ & 4.779 \\
\hline Vrolijkheid district & 4 & 1 & 0 & $0.000 \pm 0.000$ & $0.000 \pm 0.000$ & N/A \\
\hline
\end{tabular}

* The following localities had a sample size of one: Adelaide, Chelance farm, Herbertsdale, Malmesbury, Moddervlei, Montague, Oorlogskloof Reserve, Paradys, Perdefontein, Port Elizabeth, Riverlands Reserve, Rooivlei farm, Sandvlei farm and Stellenbosch.

more emphasis on PI, which depends on the final model and not the path used to obtain it, and for which a large decrease in AUC after random permutation indicates that the variable contributed strongly to the model (Phillips, 2011).

Permutation importance of BIO 19 (precipitation of the coldest quarter), contributed most to the species models for current and LGM climate scenarios (Table 3). In contrast, the PI of BIO 15 (precipitation seasonality) were highest for both clades, although its contribution is substantially higher for the western than the south-eastern clade. For all climate scenarios, precipitation makes a higher contribution than temperature did for the species and its separate clades (Table 3 ). The PI of precipitation variables under different climate scenarios varies between $89.4 \%$ and $90 \%$ for the western clade, whereas the range is between $59.2 \%$ and $61.1 \%$ for the south-eastern clade. The only temperature variable that plays a significant role in habitat suitability is mean temperature of the driest quarter (BIO 9; Table 3).

The resulting model for $H$. areolatus under current climatic conditions confirms that the species occurs predominantly on the coastal plains south-west to south-east of the GE (Fig. 2). Projections of the model onto three LGM reconstructions consistently suggest that climatically suitable space for $H$. areolatus has been larger during the LGM, (Fig. 2; Supporting Information, Fig. S2), particularly southwards across the exposed coastal shelf, but also towards the westerly interior. Thus, the species range likely expanded and contracted in response to climatic fluctuations and eustatic sea-level changes.
Current suitable habitat for the western clade is restricted to the south-west, as far east as the syntaxis zone of the CFMs. In addition, habitat with relatively low suitability exists along the western GE in the Northern Cape Province, where a relictual population of this clade occurs. LGM projections show that suitable habitat for the western clade extended not only southwards onto the exposed coastal shelf but also northwards to bridge the GE on its western side. Projections towards the south-east barely reached the syntaxis zone (Fig. 2; Supporting Information, Fig. S2).

Under current climate conditions, habitat most suitable for the south-eastern clade occurs near the coastal zone in the south and east but also further inland towards the east. The region currently showing a distributional gap between the southern and eastern subunits of the south-eastern clade display low habitat suitability (Fig. 2). LGM projections for habitat of the south-eastern clade show that suitable habitat extended mostly southwards onto the exposed coastal shelf with highest suitability westerly on the Agulhas Bank, and easterly on the coastal shelf of the Algoa Bay region. The southern region, where the species currently does not occur, had low suitability also during the LGM (Fig. 2; Supporting Information, Fig. S2). In addition, large areas of the south-eastern interior, where this clade currently occurs, had no or low habitat suitability during the LGM. Suitable habitat for the south-eastern clade also bridged the southern GE in the LGM and explains the presence of relict populations of this clade in the southern region of the Northern Cape Province. Habitat with relatively low suitability for the south-eastern clade existed 


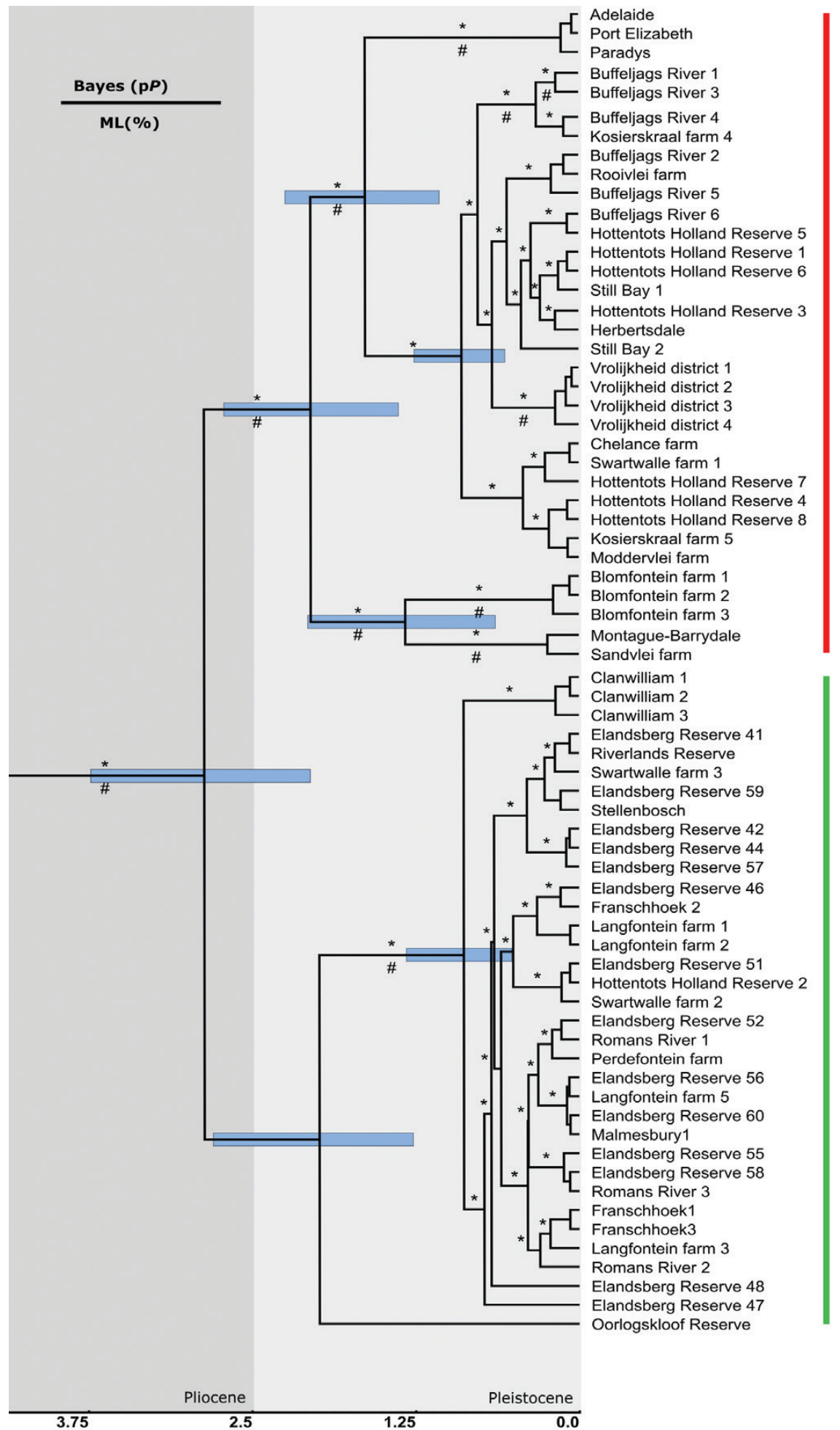

Clade 2

Clade 1

Figure 4. Bayesian phylogenetic tree based on haplotypes of mtDNA (ND4) showing Bayesian posterior probability values (PP) above the line and maximum likelihood bootstrap values $(\%)$ below the line. The asterisk (*) indicates $P \geq 0.95$ whereas the hash (\#) shows bootstrap $\geq 75 \%$. The tree also shows divergence dates in Myr as $95 \%$ highest posterior density (blue bars), calculated for mutation rates between 0.33 and 0.60 per Myr. The divergence between clade 1 (western group) and clade 2 (southern + eastern groups) occurred in the Late Pliocene. 
Table 2. Maxent values for area under the curve (AUC), with standard deviation (SD) for test values, of current and last glacial maximum (LGM) models for Homopus areolatus and clades. LGM was determined by the Community Climate System Model (CCSM4), the Max-Planck-Institute Earth System Model P (MPI-ESM-P) and the Model for Interdisciplinary Research on Climate (MIROC-ESM)

\begin{tabular}{|c|c|c|c|c|}
\hline SDM Name & Climate scenario & $\mathrm{AUC}_{\text {train }}$ & $\mathrm{AUC}_{\text {test }}$ & $\mathrm{AUC}_{\text {test }} \mathrm{SD}$ \\
\hline All & Current & 0.9412 & 0.9151 & 0.0127 \\
\hline All & LGM CCSM4 & 0.9426 & 0.9140 & 0.0131 \\
\hline All & LGM MPI-ESM-P & 0.9412 & 0.9188 & 0.0122 \\
\hline All & LGM MIROC-ESM & 0.9425 & 0.9167 & 0.0121 \\
\hline Western clade & Current & 0.9701 & 0.9628 & 0.0086 \\
\hline Western clade & LGM CCSM4 & 0.9700 & 0.9639 & 0.0084 \\
\hline Western clade & LGM MPI-ESM-P & 0.9693 & 0.9626 & 0.0086 \\
\hline Western clade & LGM MIROC-ESM & 0.9697 & 0.9613 & 0.0088 \\
\hline South-eastern clade & Current & 0.9610 & 0.9282 & 0.0153 \\
\hline South-eastern clade & LGM CCSM4 & 0.9586 & 0.9248 & 0.0152 \\
\hline South-eastern clade & LGM MPI-ESM-P & 0.9604 & 0.9243 & 0.0173 \\
\hline South-eastern clade & LGM MIROC-ESM & 0.9582 & 0.9282 & 0.0149 \\
\hline
\end{tabular}

towards the south-west in the CFMs syntaxis zone under current and LGM conditions (Fig. 2; Supporting Information, Fig. S2).

Our models indicate that the extent of suitable habitat for the species and its two clades decreased from the LGM to current climates (Supporting Information, Fig. S2; Table S3). The percentages of decrease were dependent on the LGM scenario and varied between $24 \%$ and $48 \%$ for the species as a whole, between $22 \%$ and $94 \%$ for the western clade and between $20 \%$ and $50 \%$ for the south-eastern clade. Furthermore, the models show that the two clades occupy widely distinct climatic niches with only a small intersecting area that matches the syntaxis zone (Fig. 2). The distinctiveness of the niches for the two clades is confirmed by low values for Schoener's $D$ (0.0648) and Hellingers' $I$ (0.2118), indicating little niche overlap.

The distribution of $H$. areolatus fell mainly in bioregions of the fynbos biome $(77.5 \%)$, followed by Albany Thicket (11.1\%), with little contribution from bioregions in other biomes (Supporting Information, Table S4). When considering the regions separately, fynbos remained the major vegetation type for the western $(97.5 \%)$ and southern $(89.1 \%)$ regions, whereas Albany Thicket made the most significant contribution (43.8\%) to the distribution of the eastern group (Supporting Information, Table S4).

\section{DISCUSSION}

\section{PhylogeOGRAPHY AND GENETIC DIVERGENCE}

The distribution of Homopus areolatus falls mostly within fynbos and thicket vegetation (CFR), which receive more rain than the surrounding Succulent and Nama Karoo Biomes (Rutherford et al., 2006). Much of the diversity within the GCFR is ascribed to diversification within the Pliocene and Pleistocene, and multiple reptile taxa from this region show a distinct phylogeographic pattern with western and eastern clades in the south, and northern and southern clades in the west (Tolley et al., 2014).

Homopus areolatus adheres to this west-east pattern, with clade 1 being restricted to the west and clade 2 to the south-east. These two clades abut in the syntaxis zone of the CFMs, which is also the case for several other species. For example, Daniels et al. (2007) reported distinct western and southern lineages for the angulate tortoise (Chersina angulata), and that some populations on the eastern side of syntaxis zone contain mtDNA haplotypes of the western clade, indicating recent range extension. This region also differentiates between clades of the southern rock agama, Agama atra Daudin, 1802, (Swart et al., 2009) and clades of two shrew species: forest shrews, Myosorex varius (Smuts, 1832), (Willows-Munro \& Matthee, 2011) and elephant shrews, Elephantulus edwardii (A. Smith, 1839), (Smit et al., 2007). Consequently, it appears that many species share a similar biogeographic history in this area.

Substructure within $H$. areolatus clades also conforms to geography, with both clades having representatives above the GE. The western population at Oorlogskloof Nature Reserve (on the GE) is sister to clade 1 and genetically distinct from the remaining populations further south. The Oorlogskloof population falls within a relictual fragment of fynbos vegetation that runs northwards into the Succulent Karoo (Rutherford et al., 2006). The closest, western population occurs about $100 \mathrm{~km}$ further south in the 
Table 3. Per cent contribution (PC) and permutation importance (PI) of selected environmental variables to the distribution of Homopus areolatus and its two clades for current climate and three LGM scenarios: the Community Climate System Model (CCSM4), the Max-Planck-Institute Earth System Model P (MPI-ESM-P) and the Model for Interdisciplinary Research on Climate (MIROC-ESM). BIO 2 is mean diurnal temperature range, BIO 3 is isothermality, BIO 6 is minimum temperature of the coldest month, BIO 8 is mean temperature of the warmest quarter, BIO 9 is mean temperature of the driest quarter, BIO 12 is annual precipitation, BIO 14 is precipitation of the driest month, BIO 15 is precipitation seasonality, and BIO 19 is precipitation of the coldest quarter. Variables contributing more than $10 \%$ to the model are marked in bold

\begin{tabular}{|c|c|c|c|c|c|c|}
\hline \multirow[b]{2}{*}{ CURRENT } & \multicolumn{2}{|l|}{ ALL } & \multicolumn{2}{|c|}{ WEST } & \multicolumn{2}{|c|}{ SOUTH-EAST } \\
\hline & $\mathrm{PC}$ & PI & $\mathrm{PC}$ & PI & $\mathrm{PC}$ & PI \\
\hline BIO 2 & 3.7 & 5.1 & 1.3 & 2.6 & 4.9 & 6.2 \\
\hline BIO 3 & 3.0 & 2.7 & 0.4 & 0.9 & 3.9 & 4.6 \\
\hline BIO 6 & 5.4 & 5.5 & 2.8 & 4.0 & 7.0 & 8.1 \\
\hline BIO 8 & 1.9 & 1.5 & 4.7 & 1.2 & 1.8 & 2.1 \\
\hline BIO 9 & 18.0 & 23.4 & 0.3 & 1.2 & 18.0 & 18.5 \\
\hline BIO 12 & 17.4 & 17.9 & 6.8 & 24.2 & 11.9 & 14.1 \\
\hline BIO 14 & 4.4 & 4.5 & 2.1 & 5.1 & 15.8 & 6.2 \\
\hline BIO 15 & 2.8 & 5.5 & 21.8 & $\mathbf{5 2 . 0}$ & 26.0 & 32.6 \\
\hline$\underline{\text { BIO } 19}$ & 43.3 & 33.9 & 59.8 & 8.7 & 10.7 & 7.5 \\
\hline LGM CCSM4 & $\mathrm{PC}$ & PI & $\mathrm{PC}$ & PI & $\mathrm{PC}$ & PI \\
\hline BIO 2 & 3.8 & 4.7 & 1.5 & 2.9 & 4.7 & 5.8 \\
\hline BIO 3 & 2.8 & 5.3 & 0.3 & 0.8 & 3.4 & 3.8 \\
\hline BIO 6 & 5.2 & 4.7 & 2.6 & 4.2 & 6.2 & 7.3 \\
\hline BIO 8 & 1.8 & 1.6 & 4.3 & 1.1 & 1.8 & 1.9 \\
\hline BIO 9 & 18.5 & 27.2 & 0.4 & 1.0 & 18.3 & 22.0 \\
\hline BIO 12 & 18.4 & 17.6 & 6.4 & 23.3 & 12.2 & 13.0 \\
\hline BIO 14 & 4.1 & 3.8 & 2.0 & 5.1 & 14.5 & 5.6 \\
\hline BIO 15 & 2.8 & 5.3 & 22.0 & 53.1 & 28.8 & 32.2 \\
\hline BIO 19 & 42.7 & 33.0 & 60.6 & 8.4 & 10.1 & 8.4 \\
\hline LGM MPI-ESM-P & $\mathrm{PC}$ & PI & $\mathrm{PC}$ & PI & $\mathrm{PC}$ & $\mathrm{PI}$ \\
\hline BIO 2 & 1.5 & 2.7 & 1.2 & 2.9 & 5.1 & 5.1 \\
\hline BIO 3 & 2.3 & 5.2 & 0.4 & 1.0 & 3.2 & 3.9 \\
\hline BIO 6 & 3.4 & 3.8 & 2.4 & 3.9 & 7.4 & 7.8 \\
\hline BIO 8 & 1.6 & 2.2 & 4.4 & 1.2 & 2.1 & 1.9 \\
\hline BIO 9 & 25.1 & 28.6 & 0.3 & 1.1 & 17.5 & 20.6 \\
\hline BIO 12 & 16.6 & 11.7 & 7.7 & 27.9 & 11.5 & 11.7 \\
\hline BIO 14 & 11.4 & 4.9 & 1.9 & 4.7 & 15.0 & 6.5 \\
\hline BIO 15 & 3.4 & 12.8 & 23.2 & 50.5 & 28.2 & 34.5 \\
\hline BIO 19 & 34.7 & 28.1 & 58.5 & 6.9 & 10.1 & 8.1 \\
\hline LGM MIROC-ESM & $\mathrm{PC}$ & $\mathrm{PI}$ & $\mathrm{PC}$ & $\mathrm{PI}$ & $\mathrm{PC}$ & $\mathrm{PI}$ \\
\hline BIO 2 & 2.2 & 5.9 & 1.4 & 3.0 & 4.4 & 6.1 \\
\hline BIO 3 & 3.6 & 3.1 & 0.4 & 1.0 & 4.1 & 4.5 \\
\hline BIO 6 & 4.8 & 9.9 & 2.5 & 4.3 & 6.1 & 8.4 \\
\hline BIO 8 & 3.9 & 1.4 & 4.4 & 1.2 & 2.0 & 2.3 \\
\hline BIO 9 & 16.9 & 20.3 & 0.5 & 1.2 & 18.1 & 17.7 \\
\hline BIO 12 & 21.8 & 18.7 & 7.3 & 26.6 & 11.3 & 13.0 \\
\hline BIO 14 & 4.5 & 1.9 & 1.9 & 4.5 & 16.4 & 5.1 \\
\hline BIO 15 & 1.4 & 4.8 & 22.1 & 50.2 & 27.6 & 34.9 \\
\hline BIO 19 & 40.9 & 34.0 & 59.6 & 8.1 & 10.0 & 8.1 \\
\hline
\end{tabular}


Clanwilliam district. Unfortunately, our three samples from this region came from captive individuals and their locality data are dubious. Nevertheless, these animals appear to be genetically distinct, but closely related to south-western populations of clade 1 . It is necessary to collect more samples from populations in the Clanwilliam region to confirm their position in the phylogeny. The north-south genetic differentiation in the western clade of $H$. areolatus is also seen in other species, such as C. angulata (Daniels et al., 2007), P. galeata (Vamberger et al., 2018) and E. edwardii (Smit et al., 2007), indicating that similar forces probably played a role in their divergences. The southto-north aridity gradient (Bradshaw \& Cowling, 2014) restricts the current range of $H$. areolatus to mesic vegetation types in the south-west, but the species range may have extended further north during glaciation cycles when western South Africa was more mesic (Chase \& Meadows, 2007).

Our network showed that the GE population (haplotype 13) of clade 2 is linked via populations in valleys of the CFMs (haplotypes 14 and 15) to southern coastal populations, indicating that $H$. areolatus on the GE originated from two different sources. Those GE clades are currently separated by approximately $100 \mathrm{~km}$ of Succulent Karoo vegetation, which may have prevented contact for several million years. Succulent Karoo vegetation is considered unsuitable for $H$. areolatus, which prefers more mesic conditions (Hofmeyr et al., 2005).

Clade 2 has higher genetic diversity than clade 1 , possibly because clade 2 covers a large area, bisected by the CFMs, and extends onto the GE. Consequently, high habitat heterogeneity possibly contributed to multiple local adaptations (Leffler et al., 2012). It is not clear why there is a distributional gap of $>90 \mathrm{~km}$, covered by fynbos vegetation, between the southern and eastern groups of clade 2. This gap region contains remnants of forest vegetation (Tsitsikamma forest), but it seems unlikely that forests played a significant role in the distribution and population structure of $H$. areolatus. The extent of southern forest vegetation in South Africa was already reduced by the end of the Miocene (Tolley et al., 2014), and to the west of this distribution gap, $H$. areolatus occurs to the north and south of the more extensive Knysna forest.

Our current study indicates that the two H. areolatus clades diverged in the Late Pliocene, in contrast with the results of Hofmeyr et al. (2017), who dated their divergence to the Late Miocene. The lack of dated fossil records complicate accurate dating and it seems best to assume that the divergence in $H$. areolatus may have occurred at any time during the Pliocene and Pleistocene, as has been indicated for many other plant and animal species from the GCFR (Tolley et al., 2014). Climatic changes that structured phylogenetic development in GCFR species include a progressive aridification since the Miocene, which intensified about 5-3 Mya ago, and strengthened rainfall seasonality in the west (Hoffmann et al., 2015; Neumann \& Bamford, 2015). The transition from winter to all-year rain has probably driven the west-to-east diversification in several species (Tolley et al., 2009, 2014), including $H$. areolatus. High Early Pliocene temperatures (Zachos et al., 2001) were followed by gradual cooling and fluctuations between glacial and interglacial periods for which the intensity increased from the Late Pliocene (Fedorov et al., 2006). These fluctuations would have caused repeated range contraction and expansion of species, causing genetic isolation and divergence (Tolley et al., 2014 and references therein), possibly inclusive of $H$. areolatus.

Apart from climatic variations disrupting gene flow, sea-level fluctuations during the Plio-Pleistocene also influenced species distributions and gene flow (Tolley et al., 2014). The Early Pliocene transgression (up to 350 m in South Africa; Siesser \& Dingle, 1981) would have fragmented many lowland species and may have contributed to the divergence between clades 1 and 2 of $H$. areolatus. Greater exposure of coastal forelands during the Late Pliocene regression (up to $210 \mathrm{~m}$ in South Africa; Siesser \& Dingle, 1981) would have facilitated migration between western and eastern populations, but changes in orographic rainfall rendered the south-eastern interior more arid, leading to fragmentation of mesic species (Tolley et al., 2014).

Topographic barriers seem to have had less effect on cladogenesis in $H$. areolatus than climate. Although the species distribution falls mainly in coastal forelands below the GE, both clades have representative populations above the GE and in isolated valleys of the CFMs. It is possible that these topographic barriers are not insurmountable and simply restrict movements and gene exchange. Another possibility is that populations dispersed to these regions before Pliocene uplift (Partridge, 1997) eliminated earlier dispersal routes.

\section{NICHE MODELS AND NICHE OVERLAP}

In recent years, many phylogeographic evaluations incorporated ecological niche modelling to assess if lineage and niche divergences correspond (Raxworthy et al., 2007; Rissler \& Apodaca, 2007; AlvaradoSerrano \& Knowles, 2014). Results of several studies showed that the quality of models improve when lineages are modelled separately instead of as a single unit (Gonzalez et al., 2011; Marcer et al., 2016). By modelling the entire species, it is assumed that all populations respond homogeneously to the range of environmental conditions, and the effect of local 
adaptations are overlooked (Marcer et al., 2016; Smith et al., 2019). Our results for $H$. areolatus confirmed that habitat suitability maps were more informative when clades were modelled separately. For example, the distribution map for the whole species did not delineate differences between clade 1 and clade 2, whereas habitat suitability maps of the separate clades clearly indicated niche separation.

Habitat suitability in the LGM provides information on refugia under glaciation conditions to assess if suitable habitats shifted, contracted or expanded between glacial and interglacial periods (Barlow et al., 2013; Tolley et al., 2014). However, despite several years of research, there is still no consensus about regional climatic conditions in southern Africa during the LGM (Stone, 2014). Most lines of evidence point towards temperatures being $2-6{ }^{\circ} \mathrm{C}$ lower than today, and that conditions were more mesic in the west, whilst drier in the south and east, compared to the present (Stone, 2014 and references therein). Our results for $H$. areolatus show that suitable habitat for the species and the clades shrank from the LGM to present. Habitat shrinkage can be ascribed mostly to higher sea-levels now covering previously exposed coastal forelands (Agulhas Bank). However, there were also changes towards the interior. Suitable habitat for the western clade does no longer extend as far north as during the LGM, whereas habitat suitability of the south-eastern clade increased towards the interior. Consequently, habitat for the western clade remained largely in the same region (although smaller) but suitable habitat for the south-eastern clade shifted northwards to cover larger parts of the interior. It appears as if the southern and eastern subgroups of the south-eastern clade may have had different refugial areas in the LGM, which may explain why these subgroups are genetically distinct. More research is necessary to understand why we found a single haplotype from three localities, separated by a distance of up to $200 \mathrm{~km}$, in the east.

Habitat suitability of the western clade is strongly linked to rainfall seasonality (BIO 15; winter rains and summer aridity) both during the LGM and currently, but annual precipitation (BIO 12) also makes a substantial contribution. It appears as if rainfall rather than temperature was the major driving force to differentiate the western clade. Habitat shrinkage in the west since the LGM is probably due to lower current rainfall (Chase \& Meadows, 2007), which reduced highly suitable habitat (Fig. 2) to a small region in the south-west. Rainfall seasonality (BIO 15) and annual precipitation (BIO 12) are also of PI to southeastern habitat suitability, currently and in the LGM, but not to the same extent as in the west. Temperature plays a greater role in the south-east than in the west. There is evidence that the southern region was more arid in the LGM than currently (Chase \& Meadows, 2007) and that changes in orographic rainfall rendered the south-eastern interior more arid (Tolley et al., 2014). These factors probably contributed to reduced suitable habitat in the south-eastern interior during the LGM with suitable habitat being restricted mainly to the exposed seafloor. When the south-east became more mesic under current conditions, suitable habitat extended northwards into the interior, simultaneously with reduced habitat in the south due to an elevated sea-level. The co-occurrence of the two genetically differentiated clades at two sites in the syntaxis zone may indicate recent range extension of one or both clades, but this needs further investigation because incomplete lineage sorting (Smit et al., 2007) may also account for this pattern.

The ranges of the western and south-eastern clades fall predominantly in the Fynbos Biome, inclusive of Renosterveld. Fynbos in the southern region is interspersed with succulent Karoo, a more arid vegetation type (Rutherford et al., 2006), and small patches of Albany Thicket, mostly confined to lower mountain slopes and some river valleys (Hoare et al., 2006). The few records for $H$. areolatus in succulent Karoo in the south may be due to inaccurate coordinates or low resolution of vegetation mapping. Towards the east, populations fall mostly in Albany Thicket (43.8\%), although fynbos (26.6\%) features strongly, and the species has reasonable representation in several other biomes. The extent of thicket declined with past increases in aridity and it is now restricted mostly to south-eastern South Africa, where greater incised valleys, relative to the west, provide frost-free refugia for this subtropical vegetation (Cowling et al., 2009; Hoffmann et al., 2015). Albany Thicket consists of a dense growth of shrubs or trees (Hoare et al., 2006), which does not seem ideal for small tortoises. Recent opening-up of thicket due to agricultural practices may have made thicket more suitable for tortoises, but the situation with this group seems to be more complex and requires additional research.

The small niche overlap between the western and south-eastern clades supports the notion that genetic differentiation in $H$. areolatus is accompanied by niche divergence, as has been shown for several species, e.g. Peromyscus maniculatus (Wagner, 1845) (Kalkvik et al., 2012) and Ochthebius glaber (Montes \& Soler, 1988) (Sánchez-Fernández et al., 2011). The small range size of western $H$. areolatus may put this clade at risk, as geographic range size is a key predictor of extinction (Saupe et al., 2015). Furthermore, the habitat of this clade is largely destroyed by cultivation and urban development, with evidence that habitat degradation is continuing [see fig. 5 in Schoeman et al. (2013)]. This raises the question if the two H. areolatus clades represent distinct taxonomic units. Uncorrected 
p-distances of the Cytb gene are often used as proxy to assess the taxonomic status of tortoises and turtles, but the range is wide and varies from $3.7 \%$ to $12.7 \%$ for congeneric tortoise species (Fritz et al., 2012). The uncorrected ND4 p-distance of $3.38 \%$ between the two $H$. areolatus clades does not supply sufficient information for taxonomic decisions and more dense sampling in the zone of overlap and the use of more genetic loci are required to answer this question. Nevertheless, all evidence indicates that it would be prudent to treat the two clades at this stage as separate management units.

\section{CONCLUSION}

Our results for $H$. areolatus supported the contention that Pliocene-Pleistocene climate change shaped the phylogenetic structure of many CFR taxa. Climate change established abiotic gradients over the distribution range of $H$. areolatus, and local adaptations probably contributed to the diversification and genetic structure of the species. We propose that the west-east rainfall seasonality gradient was the primary factor driving divergence between the two clades, with the western clade being restricted to the winter rainfall zone, whilst the south-eastern clade falls in the all-year rainfall zone. It seems likely that this divergence occurred during the Early to Middle Pliocene, which corresponds with the period when the Benguela Current intensified and the western winter-rainfall regime became firmly established (Rommerskirchen et al., 2011; Hoffmann et al., 2015 and references therein). The south-eastern all-year rainfall zone also shows a rainfall seasonality gradient with winter rains being more predictable west, and summer rains more predictable east, of $23^{\circ} \mathrm{E}$ (Cowling et al., 2017). This transition zone corresponds to the western border of the distribution gap between the southern and eastern groups of clade 2, rendering the eastern group more reliant on summer rains. Abiotic differences between the southern and eastern groups were reflected in vegetation changing from fynbos to thicket, from the south to the east, possibly contributing to local adaptations.

This study represents one of few studies that combined phylogenetic evaluations of a South African species with niche modelling. We demonstrate that niche models of separate clades are more informative than when the species is treated as a single unit, and show that abiotic differences over the species range could explain the genetic structure of $H$. areolatus. A comparison of habitat suitability during glaciation and interglacial periods show habitat contraction since the LGM, which has conservation implication for the western clade of $H$. areolatus that is already threatened by agricultural and urban expansion. We recommend that future niche evaluations of South African species should treat clades separately to better understand the effect of abiotic factors on genetic divergence, and the possible effects of climate change on the conservation status of species and their clades.

\section{ACKNOWLEDGEMENTS}

We are grateful to all farmers who allowed us to take samples from tortoises on their properties, and conservation agencies for research permits: CapeNature AAA007-00071-0056 and AAA007-002120056; Northern Cape Province 595/2009, 245/2015 and 0729/2018; Eastern Cape Province CRO 117/13CR and CRO 118/13CR. This research was done under ethics clearance numbers ScRiRC2008/39 and AR 19/4/1 from the University of the Western Cape. We also acknowledge financial support to MDH and SRD from the National Research Foundation and, respectively, from the Universities of the Western Cape and Stellenbosch.

This article is dedicated to the first author, the late Prof. Retha Hofmeyr for her outstanding commitment to tortoise research in southern Africa. Retha, we will miss your work ethic, your passion for the veld and that joyous infectious laugh of yours. You were a star lecturer and a dedicated researcher. Thank you for your generosity. It was an honour for me, as a student, and now as a fellow academic to work with you on what was to be our final paper. I salute you.

\section{REFERENCES}

Aguirre-Gutiérrez J, Serna-Chavez HM, VillalobosArambula AR, Pérez de la Rosa JA, Raes N. 2015. Similar but not equivalent: ecological niche comparison across closely-related Mexican white pines. Diversity and Distributions 21: 245-257.

Alvarado-Serrano DF, Knowles LL. 2014. Ecological niche models in phylogeographic studies: applications, advances and precautions. Molecular Ecology Resources 14: 233-248.

Barlow A, Baker K, Hendry CR, Peppin L, Phelps T, Tolley KA, Wüster CE, Wüster WG. 2013. Phylogeography of the widespread African puff adder (Bitis arietans) reveals multiple Pleistocene refugia in southern Africa. Molecular Ecology 22: 1134-1157.

Bates MF, Branch WR, Bauer AM, Burger M, Marais J, Alexander GJ, de Villiers MS. 2014. Atlas and red list of the reptiles of South Africa, Lesotho and Swaziland. Pretoria: South African National Biodiversity Institute.

Boria RA, Olson LE, Goodman SM, Anderson RP. 2014. Spatial filtering to reduce sampling bias can improve the performance of ecological niche models. Ecological Modelling 275: $73-77$. 
Born J, Linder HP, Desmet P. 2007. The Greater Cape Floristic Region. Journal of Biogeography 34: 147-162.

Bowen BW, Meylan AB, Ross JP, Limpus CJ, Balazs GH, Avise JC. 1992. Global population structure and natural history of the green turtle (Chelonia mydas) in terms of matriarchal phylogeny. Evolution 46: 865-881.

Bradshaw PL, Cowling RM. 2014. Landscapes, rock types, and climate of the Greater Cape Floristic Region. In: Allsopp N, Colville JF, Verboom A, eds. Fynbos: ecology, evolution, and conservation of a megadiverse region. Oxford: Oxford University Press, 26-46.

Branch B. 2008. Tortoises, terrapins \& turtles of Africa. Cape Town: Struik Publishers.

Brown JL. 2017. SDMtoolbox: a python-based GIS toolkit for landscape genetic, biogeographic and species distribution model analyses. Available at: http://www.sdmtoolbox.org/ data/sdmtoolbox/current/User_Guide_SDMtoolbox.pdf (date last accessed, 2019).

Brown JL, Bennett JR, French CM. 2017. SDMtoolbox 2.0: the next generation Python-based GIS toolkit for landscape genetics, biogeography and species distribution model analyses. PeerJ 5: e4095.

Burke K, Gunnell Y. 2008. The African erosion surface: a continental-scale synthesis of geomorphology, tectonics, and environmental change over the past 180 million years. Geological Society of America Memoirs 201: 1-66.

Caccone A, Amato G, Gratry OC, Behler J, Powell JR. 1999. A molecular phylogeny of four endangered Madagascar tortoises based on mtDNA sequences. Molecular Phylogenetics and Evolution 12: 1-9.

Chase BM, Meadows ME. 2007. Late Quaternary dynamics of southern Africa's winter rainfall zone. Earth-Science Reviews 84: 103-138.

Clark VR, Barker NP, Mucina L. 2011. The Great Escarpment of southern Africa: a new frontier for biodiversity exploration. Biodiversity and Conservation 20: 2543-2561.

Clement M, Posada D, Crandall KA. 2000. TCS: a computer program to estimate gene genealogies. Molecular Ecology 9: 1657-1659.

Cooper MR, Broadley DG. 1990. A new species of fossil Homopus (Cryptodira: Testudinidae) from South Africa. Studia Palaeocheloniologica 3: 41-55.

Cowling RM, Procheş ş, Vlok JHJ. 2005. On the origin of southern African subtropical thicket vegetation. South African Journal of Botany 71: 1-23.

Cowling RM, Procheş S, Partridge TC. 2009. Explaining the uniqueness of the Cape flora: incorporating geomorphic evolution as a factor for explaining its diversification. Molecular Phylogenetics and Evolution 51: 64-74.

Cowling RM, Bradshaw PL, Colville JF, Forest F. 2017. Levyns' law: explaining the evolution of a remarkable longitudinal gradient in Cape plant diversity. Transactions of the Royal Society of South Africa 72: 184-201.

Daniels SR, Hofmeyr MD, Henen BT, Crandall KA. 2007. Living with the genetic signature of Miocene induced change: evidence from the phylogeographic structure of the endemic angulate tortoise Chersina angulata. Molecular Phylogenetics and Evolution 45: 915-926.
Daniels SR, Hofmeyr MD, Henen BT, Baard EHW. 2010. Systematics and phylogeography of a threatened tortoise, the speckled padloper. Animal Conservation 13: 237-246.

Excoffier L, Laval G, Schneider S. 2005. Arlequin v.3.0: an integrated software package for population genetics data analysis. Evolutionary Bioinformatics 1: 47-50.

Fedorov AV, Dekens PS, McCarthy M, Ravelo AC, DeMenocal PB, Barreiro M, Pacanowski RC, Philander SG. 2006. The Pliocene paradox (mechanisms for a permanent El Niño). Science 312: 1485-1489.

Felsenstein J. 1985. Confidence limits on phylogenies: an approach using the bootstrap. Evolution 39: 783-791.

Fick SE, Hijmans RJ. 2017. Worldclim 2: new 1-km spatial resolution climate surfaces for global land areas. International Journal of Climatology 37: 4302-4315.

Fritz U, Daniels SR, Hofmeyr MD, González J, BarrioAmorós CL, Siroky P, Hundsdörfer AK, Stuckas H. 2010. Mitochondrial phylogeography and subspecies of the wide-ranging, sub-Saharan leopard tortoise Stigmochelys pardalis (Testudines: Testudinidae) - a case study for the pitfalls of pseudogenes and GenBank sequences. Journal of Zoological Systematics and Evolutionary Research 48: 348-359.

Fritz U, Alcalde L, Vargas-Ramírez M, Goode EV, FabiusTuroblin DU, Praschag P. 2012. Northern genetic richness and southern purity, but just one species in the Chelonoidis chilensis complex. Zoologica Scripta 41: 220-232.

Fu YX. 1997. Statistical tests of neutrality of mutations against population growth, hitchhiking and background selection. Genetics 147: 915-925.

Gonzalez SC, Soto-Centeno JA, Reed DL. 2011. Population distribution models: species distributions are better modeled using biologically relevant data partitions. BMC Ecology 11: 20 (https://doi.org/10.1186/1472-6785-11-20).

Grab S, Knight J. 2015. Landscapes and landforms of South Africa - an overview. In: Grab S, Knight J, eds. Landscapes and landforms of South Africa. Cham: Springer International Publishing, 1-9.

Green PF, Duddy IR, Japsen P, Bonow JM, Malan JA. 2017. Post-breakup burial and exhumation of the southern margin of Africa. Basin Research 29: 96-127.

Hasumi H, Emori S. 2004. $K-1$ coupled GCM (MIROC) description. Tokyo: Center for Climate System Research, University of Tokyo (K-1 Technical Report No. 1).

Hewitt G. 2000. The genetic legacy of the Quaternary ice ages. Nature 405: 907-913.

Hijmans RJ, Cameron SE, Parra JL, Jones PG, Jarvis A. 2005. Very high resolution interpolated climate surfaces for global land areas. International Journal of Climatology 25: 1965-1978.

Hoare DB, Mucina L, Rutherford MC, Vlok JHJ, EustonBrown DIW, Palmer AR, Powrie LW, LechmereOertel RG, Procheş SM, Dold AP, Ward RA. 2006. Albany Thicket Biome. In: Mucina L, Rutherford MC, eds. The vegetation of South Africa, Lesotho and Swaziland. Pretoria: South African Biodiversity Institute, 540-567.

Hoffmann V, Verboom GA, Cotterill FP. 2015. Dated plant phylogenies resolve neogene climate and landscape evolution in the Cape Floristic Region. PLoS One 10: e0137847. 
Hofmeyr MD, Branch WR. 2018. The padloper's tortuous path (Chelonia: Testudinidae): two genera, not one. African Journal of Herpetology 67: 99-112.

Hofmeyr MD, Henen BT, Loehr VJT. 2005. Overcoming environmental and morphological constraints: egg size and pelvic kinesis in the smallest tortoise, Homopus signatus. Canadian Journal of Zoology 83: 1343-1352.

Hofmeyr MD, Boycott RC, Baard EHW. 2014. Family Testudinidae. In: Bates MF, Branch WR, Bauer AM, Burger M, Marais J, Alexander GJ, de Villiers MS, eds. Atlas and red list of the reptiles of South Africa, Lesotho and Swaziland. Pretoria: South African Biodiversity Institute, 70-85.

Hofmeyr MD, Vamberger M, Branch W, Schleicher A, Daniels SR. 2017. Tortoise (Reptilia, Testudinidae) radiations in Southern Africa from the Eocene to the present. Zoologica Scripta 46: 389-400.

Ives I, Spinks PQ, Shaffer HB. 2008. Morphological and genetic variation in the endangered Sulawesi tortoise Indotestudo forstenii: evidence of distinct lineages? Conservation Genetics 9: 709-713.

Kalkvik HM, Stout IJ, Doonan TJ, Parkinson DL. 2012. Investigating niche and lineage diversification in widely distributed taxa: phylogeography and ecological niche modelling of the Peromyscus maniculatus species group. Ecography 35: 54-64.

Lamb T, Lydeard C, Walker RB, Gibbons JW. 1994. Molecular systematics of map turtles (Graptemys): a comparison of mitochondrial restriction site versus sequence data. Systematic Biology 43: 543-559.

Leffler EM, Bullaughey K, Matute DR, Meyer WK, Ségurel L, Venkat A, Andolfatto P, Przeworski M. 2012. Revisiting an old riddle: what determines genetic diversity levels within species? PLoS Biology 10: e1001388.

Linder HP. 2008. Plant species radiations: where, when, why? Philosophical Transactions of the Royal Society B 363: 3097-3105.

Marcer A, Méndez-Vigo B, Alonso-Blanco C, Picó FX. 2016. Tackling intraspecific genetic structure in distribution models better reflects species geographical range. Ecology and Evolution 6: 2084-2097.

Moore A, Blenkinsop T, Cotterill F. 2009. Southern African topography and erosion history: plumes or plate tectonics? Terra Nova 21: 310-315.

Neumann FH, Bamford MK. 2015. Shaping of modern southern African biomes: Neogene vegetation and climate change. Transactions of the Royal Society of South Africa 70: 195-212.

Nicolas V, Mataame A, Chochet P-A, Geniez P, Fahd S, Ohler A. 2018. Phylogeography and ecological niche modelling unravel the evolutionary history of the African green toad, Bufotes boulengeri (Amphibia: Bufonidae), through the Quaternary. Journal of Zoological Systematics and Evolutionary Research 56: 102-116.

Otto-Bliesner BL, Brady EC, Clauzet G, Tomas R, Levis S, Kothavala Z. 2006. Last glacial maximum and Holocene climate in CCSM3. Journal of Climate 19: 2526-2544.

Parham JF, Türkozan O, Stuart BL, Arakelyan M, Soheila S, Macey JR, Werner YL, Papenfuss TJ. 2006. Genetic evidence for premature taxonomic inflation in middle eastern tortoises. Proceeding of the California Academy of Sciences 57: 955-964.

Partridge TC. 1997. Evolution of landscapes. In: Cowling RM, Richardson DM, Pierce SM, eds. Vegetation of Southern Africa. Cambridge: Cambridge University Press, $5-20$.

Partridge TC, Dollar ESJ, Moolman J, Dollar LH. 2010. The geomorphic provinces of South Africa, Lesotho and Swaziland: a physiographic subdivision for earth and environmental scientists. Transactions of the Royal Society of South Africa 65: 1-47.

Phillips SJ. 2011. A brief tutorial on Maxent. Princeton: AT\&T Research.

Phillips SJ, Dudík M. 2008. Modeling of species distributions with MAXENT: new extensions and a comprehensive evaluation. Ecography 31: 161-175.

Phillips SJ, Anderson RP, Schapire RE. 2006. Maximum entropy modelling of species geographic distributions. Ecological Modelling 190: 231-259.

Phillips SJ, Dudík M, Schapire RE. 2019. Maxent software for modeling species niches and distributions (v.3.4.1). Available at: http://biodiversityinformatics.amnh.org/open_ source/maxent/ (accessed 18 November 2019).

Posada D, Crandall KA. 1998. MODELTEST: testing the model of DNA substitution. Bioinformatics 14: 817-818.

Raxworthy CJ, Ingram CM, Rabibisoa N, Pearson RG. 2007. Applications of ecological niche modelling for species delimitation: a review and empirical evaluation using day geckos (Phelsuma) from Madagascar. Systematic Biology 56: 907-923.

Rissler LJ, Apodaca JJ. 2007. Adding more ecology into species delimitation: ecological niche models and phylogeography help define cryptic species in the black salamander (Aneides flavipunctatus). Systematic Biology 56: 924-942.

Rommerskirchen F, Condon T, Mollenhauer G, Dupont L, Schefuss E. 2011. Miocene to Pliocene development of surface and subsurface temperatures in the Benguela Current system. Paleoceanography 26: PA3216.

Ronquist F, Huelsenbeck JP. 2003. MrBayes 3: Bayesian phylogenetic inference under mixed models. Bioinformatics 19: $1572-1574$.

Rutherford MC, Mucina L, Powrie LW. 2006. Biomes and bioregions of Southern Africa. In: Mucina L, Rutherford MC, eds. The vegetation of South Africa, Lesotho and Swaziland. Pretoria: South African Biodiversity Institute, 30-51.

Sánchez-Fernández D, Lobo JM, Abellán P, Millán A. 2011. Environmental niche divergence between genetically distant lineages of an endangered water beetle. Biological Journal of the Linnean Society 103: 891-903.

Saupe EE, Qiao H, Hendricks JR, Portell RW, Hunter SJ, Soberón J, Lieberman BS. 2015. Niche breadth and geographic range size as determinants of species survival on geological time scales. Global Ecology and Biogeography 24: 1159-1169.

Schoeman F, Newby TS, Thompson MW, van den Berg EC. 2013. South African land-cover change map. South African Journal of Geomatics 2: 94-105. 
Searcy CA, Shaffer HB. 2016. Do ecological niche models accurately identify climatic determinants of species ranges? The American Naturalist 187: 423-435.

Shaffer HB, Minx P, Warren DE, Shedlock AM, Thomson RC, Valenzuela N, Abramyan J, Amemiya CT, Badenhorst D, Biggar KK, Borchert GM, Botka CW, Bowden RM, Braun EL, Bronikowski AM, Bruneau BG, Buck LT, Capel B, Castoe TA, Czerwinski M, Delehaunty KD, Edwards SV, Fronick CC, Fujita MK, Fulton L, Graves TA, Green RE, Haerty W, Hariharan R, Hernandez O, Hillier LW, Holloway AK, Janes D, Janzen FJ, Kandoth C, Kong L, de Koning AP, Li Y, Literman R, McGaugh SE, Mork L, O'Laughlin M, Paitz RT, Pollock DD, Ponting CP, Radhakrishnan S, Raney BJ, Richman JM, St John J, Schwartz T, Sethuraman A, Spinks PQ, Storey KB, Thane N, Vinar T, Zimmerman LM, Warren WC, Mardis ER, Wilson RK. 2013. The western painted turtle genome, a model for the evolution of extreme physiological adaptations in a slowly evolving lineage. Genome Biology 14: R28.

Siesser WG, Dingle RV. 1981. Tertiary sea-level movements around Southern Africa. Journal of Geology 89: 83-96.

Smit HA, Robinson TJ, Van Vuuren BJ. 2007. Coalescence methods reveal the impact of vicariance on the spatial genetic structure of Elephantulus edwardii (Afrotheria, Macroscelidea). Molecular Ecology 16: 2680-2692.

Smith AB, Godsoe W, Rodríguez-Sánchez F, Wang H-H, Warren DL. 2019. Niche estimation above and below the species level. Trends in Ecology \& Evolution 34: 260-273.

Swets JA. 1988. Measuring the accuracy of diagnostic systems. Science 240: 1285-1293.

Swart BL, Tolley KA, Matthee CA. 2009. Climate change drives speciation in the southern rock agama (Agama atra) in the Cape Floristic Region, South Africa. Journal of Biogeography 36: 78-87.

Stone A. 2014. Last glacial maximum conditions in southern Africa: are we any closer to understanding the climate of this time period? Progress in Physical Geography: Earth and Environment 38: 519-542.

Swofford DL. 2002. PAUP*: phylogenetic analysis using parsimony (and other methods), v.4.10. Sunderland: Sinauer Associates.

Thompson JD, Gibson TJ, Plewniak F, Jeanmougin F, Higgins DG. 1997. The Clustal $X$ windows interface: flexible strategies for multiple sequence alignment aided by quality analysis tools. Nucleic Acids Research 24: 4876-4882.

Tolley KA, Makokha JS, Houniet DT, Swart BL, Matthee CA. 2009. The potential for predicted climate shifts to impact genetic landscapes of lizards in the South African Cape Floristic Region. Molecular Phylogenetics and Evolution 51: 120-130.

Tolley KA, Bowie RCK, Measey GJ, Price BW, Forest F. 2014. The shifting landscape of genes since the Pliocene: terrestrial phylogeography in the Greater Cape Floristic Region. In: Allsopp N, Colville JF, Verboom A, eds. Fynbos: ecology, evolution, and conservation of a megadiverse region. Oxford: Oxford University Press, 142-163.

Townsend TM, Alegre RE, Kelly ST, Wiens JJ, Reeder TW. 2008. Rapid development of multiple nuclear loci for phylogenetic analysis using genomic resources: an example from squamate reptiles. Molecular Phylogenetics and Evolution 47: 129-142.

Vamberger M, Hofmeyr MD, Ihlow F, Fritz U. 2018. In quest of contact: phylogeography of helmeted terrapins (Pelomedusa galeata, P. subrufa sensu stricto). PeerJ 6: e4901.

VanDerWal J, Shoo LP, Graham C, Williams SE. 2009. Selecting pseudo-absence data for presence-only distribution modelling: how far should you stray from what you know? Ecological Modelling 220: 589-594.

Verboom GA, Linder HP, Forest F, Hoffmann V, Bergh NG, Cowling RM 2014. Cenozoic assembly of the Greater Cape Flora. In: Allsopp N, Colville JF, Verboom A, eds. Fynbos: ecology, evolution, and conservation of a megadiverse region. Oxford: Oxford University Press, 93-118.

Wang B, Xie F, Li J, Wang G, Li C, Jiang J. 2017. Phylogeographic investigation and ecological niche modelling of the endemic frog species Nanorana pleskei revealed multiple refugia in the eastern Tibetan Plateau. PeerJ 5: e3770.

Warren DL, Glor RE, Turelli M. 2008. Environmental niche equivalency versus conservatism: quantitative approaches to niche evolution. Evolution 62: 2868-2883.

Warren DL, Glor RE, Turelli M. 2010. ENMTools: a toolbox for comparative studies of environmental niche models. Ecography 33: 607-611.

Willows-Munro S, Matthee CA. 2011. Linking lineage diversification to climate and habitat heterogeneity: phylogeography of the Southern African shrew Myosorex varius. Journal of Biogeography 38: 1976-1991.

Zachos J, Pagani M, Sloan L, Thomas E, Billups K. 2001. Trends, rhythms, and aberrations in global climate $65 \mathrm{Ma}$ to present. Science 292: 686-693.

Zhu G-P, Li H-Q, Zhao L, Man L, Liu Q. 2016. Mapping the ecological dimensions and potential distributions of endangered relic shrubs in western Ordos biodiversity center. Scientific Reports 6: 26268.

\section{SUPPORTING INFORMATION}

Additional Supporting Information may be found in the online version of this article at the publisher's web-site.

Figure S1. Fixed distance radial buffers of $200 \mathrm{~km}$ to define bias files for occurrence records of all Homopus areolatus localities (left), the western clade (clade 1: middle), and the south-eastern clade (clade 2: right). Localities represent spatially filtered occurrence data to a single point within a Euclidian distance of $2.5 \mathrm{~km}$ to 
remove spatial autocorrelation. Note that some localities, apart from genetic samples, have been removed from the syntaxis zone where the two clades overlap before running the models for individual clades.

Figure S2. Overlays of Homopus areolatus current on LGM habitat, corrected for overprediction. LGM habitat includes exposed seafloor to the south and west of the current shoreline. Suitable habitat is shown as three different shades of grey that are darker than the background colour. The dark grey reflects habitat that overlapped during current and LGM climates; the medium grey Illustrates current suitable habitat that was not available during the LGM; and the light grey represents additional suitable habitat during the LGM. The three columns from left to right illustrate, respectively, habitat suitability for the species, the western and the south-eastern clades. The three rows from top to bottom show, respectively, results for Community Climate System Model (CCSM4), the Max-Planck-Institute Earth System Model P (MPI-ESM-P) and the Model for Interdisciplinary Research on Climate (MIROC-ESM).

Table S1. Locality, clade and coordinates of Homopus areolatus individuals used for phylogeographic evaluation. Table S2. List of the haplotype frequencies for each sample locality of Homopus areolatus.

Table S3. Areas of Homopus areolatus suitable habitat $\left(\mathrm{km}^{2}\right)$, corrected for overprediction, in different regions under Last Glacial Maximum (LGM) and current conditions, as well as the difference in area between the two periods. LGM was determined by the Community Climate System Model (CCSM4), the Max-Planck-Institute Earth System Model P (MPI-ESM-P) and the Model for Interdisciplinary Research on Climate (MIROC-ESM).

Table S4. Association of Homopus areolatus with vegetation biomes and bioregions according to Rutherford et al. (2006). Total values per biome are shown in bold. The south-east is divided into south and east to demonstrate how Fynbos transition into Albany Thicket from the south to the east. 